\title{
Los Anclajes Socio-existenciales: El Caso de las Expectativas de Futuro
}

\author{
Kathya Araujo \\ Universidad de Santiago de Chile, Santiago, Chile. E-mail: kathya.arauj@gmail.com
}

\begin{abstract}
I a consideración del individuo, como entidad empírica y / o norma-
Liva (Dumont, 1987), por la sociología es de larga data. De hecho, la presencia teórica del individuo puede ser rastreada, y más allá de sus diferencias, desde autores clásicos como Weber, Durkheim o Simmel, dada su aguda consciencia de que los procesos de diferenciación social y el avance de la individualización iban de la mano (Kippele, 1998; Schroer, 2000). Por supuesto, también, el individuo ha estado, de diferentes maneras, presente en el interés de autores llamados post-clásicos, como Parsons (1964), Merton (2002) o Riesman (1981), y ha jugado un papel destacado en las discusiones contemporáneas sobre individualización e individualismo, por ejemplo en los desarrollos de los llamados teóricos de la segunda modernidad (Beck, 1998; Giddens, 1997). Sin embargo, uno de los rasgos de la sociología en su intento por pensarlo, ha sido su tendencia a no considerar suficientemente los rendimientos del propio individuo para sostenerse en lo social. Es este precisamente el campo de interés en el que se sitúa este artículo.
\end{abstract}

El objetivo que nos proponemos es, luego de discutir teóricamente las modalidades posibles de abordaje de esta dimensión, presentar, a partir de los resultados de una investigación empírica para el caso de Chi$\mathrm{le}^{1}$, el análisis de este trabajo de sostenimiento de los individuos en lo social, centrándonos en la cuestión de los "anclajes socio-existenciales", y en particular en un tipo de estos: las maneras en que ciertos eleDADOS - Revista de Ciências Sociais, Rio de Janeiro, vol. 61, no-2, 2018, pp. 341 a 371. 
mentos constituidos como fundamentos de las expectativas de futuro actúan como anclas para las existencias sociales. La discusión de estos resultados, permitirá argumentar que los anclajes socio-existenciales son activos en los individuos concretos pero son socialmente compartidos y pueden ser entendidos como una respuesta, con matices según grupo social, a la vez singular y general, a las exigencias estructurales a las que se está expuesto en un momento histórico determinado. En consecuencia, el artículo está dividido en tres partes. La primera está destinada a situar el contexto de los debates teóricos en que este texto se ubica. La segunda servirá para presentar las premisas y nociones con las que se propone abordar el estudio de este ámbito. En la tercera parte, y sobre la base de los resultados de la investigación empírica, se analizará una dimensión que, en el contexto de los desafíos estructurales actuales, se constituye como una destacada ancla para las existencias sociales de los individuos en la sociedad chilena: el sur - campo como expectativa de futuro.

\section{EL DEBATE TEÓRICO}

Existen múltiples perspectivas en las que el estudio del agente empíri$\mathrm{co}$, entendido desde la noción de individuo o de sujeto, ha sido enfocado como fuente para la comprensión de las sociedades o de lo social, pero solo la menor parte ha supuesto la importancia del trabajo del propio agente empírico para esta comprensión, y, mucho menos aún son aquellas perspectivas que han asumido que la inteligibilidad de lo social se enriquecería con el análisis del trabajo que estos despliegan para sostenerse en la vida social. Con frecuencia el caso ha sido que el análisis de los rendimientos para sostenerse en lo social ha sido catalogado como una tarea de la psicología y no como un objeto sociológico.

Una razón de peso para lo anterior es, sin duda, la tendencia a considerar que este es un trabajo que concierne a una dimensión "interior" o "existencial", y que estas cuestiones serían puramente individuales. Puesto de otra manera, se trata de la suposición que la vida social no es un hecho existencial y que las personas lidian con este tipo de experiencias o requerimientos desde una clave distinta de aquella que movilizan respecto de sus existencias personales. Lo anterior a pesar de la evidencia que fenómenos en apariencia individuales como por ejemplo la depresión o el suicidio, como ya lo explicaba Durkheim, pueden, y deben, ser entendidos no solo como expresiones de contingencias puramente individuales sino también como formas de respuesta al tipo 
de exigencias que ponen las sociedades a sus individuos en determinados momentos históricos (Ehrenberg, 2000, 2010; Otero, 2012).

La segunda explicación para esta obliteración puede encontrarse en el hecho de que para muchas de las teorías sociales la cuestión del sostén del individuo aparece como una pregunta innecesaria dada la importancia que se le otorga a las estructuras, a los regímenes de dominación o al aparataje institucional. El sostén en el mundo, en estos casos, no es una pregunta porque resulta un dato de entrada. Lo que se trata de saber desde estas perspectivas es más bien las maneras específicas en que el agente está ya tomado por lo social y es "hecho" actuar en y por este entramado, como lo muestran la teoría disposicionalista de Bourdieu y la funcional normativista de Parsons. En efecto, estas tesis constituyen un avance, respecto a la férrea indiferencia al agente empírico exhibida por el marxismo funcionalista o el estructuralismo (Portocarrero, 2006). A diferencia de estas últimas, ellas suponen que la conducta no es efecto directo de la estructura sino que existen procesos mediadores entre la acción y la estructura, como lo revelan la noción de habitus de la teoría disposicionalista (Bourdieu, 1989; Bourdieu y Wacquant, 1995) o la interiorización de las normas postulada por Parsons (1964). Se impone una direccionalidad y correspondencia relativamente estricta porque la idea central que subyace aquí es que la comprensión de las acciones y experiencias de los agentes empíricos pueden ser derivadas en gran medida de su posición social. Por lo tanto, un objetivo central en ellas es explicar el mecanismo de ajuste entre el agente empírico y una posición social. El punto de partida es que el agente está intrínsecamente anudado por la sociedad y, por lo tanto, es posible imaginarlo como inherentemente sostenido (sea que se asocie a términos positivos adaptativos o negativos de dominación) por ella. La existencia social vendría garantizada por los mecanismos de integración. Sostén e integración son hechos equivalentes. Los diferenciales entre los individuos así como la abierta contingencia de su acción al calor de la vida social no son considerados cabalmente desde estas posiciones precisamente porque el sostén en lo social aparece como dado y, en consecuencia, en cuanto problema sociológico carece de interés y significación.

Es este mismo supuesto de entrada el que se encuentra en perspectivas que subrayan la transformación de las instituciones y la concomitante emergencia de un nuevo proceso de individualización (Beck, 1998; Beck y Beck-Gernsheim, 2003; Giddens, 1997, 1998; Bauman, 2001; Kron, 2000; Simonson, 2004; Le Bart, 2009; Gross, 1994; Nollman y 
Strasser, 2004), o, también, en los trabajos de las primeras fases de Foucault, en los que subjetivación y sujeción tienden a recubrirse (Foucault, 1983). En estos casos, y a pesar del esfuerzo realizado, las estructuras - sea por intermediación de las instituciones o de los dispositivos de poder y saber - pivotean la comprensión, de manera que el trabajo específico que los agentes efectúan es concebido como un mero resultado de las prescripciones institucionales.

Una tercera razón para no poner atención a las modalidades en que los individuos se sostienen en lo social se vincula con el estatuto puramente expresivo que se le ha dado a lo individual para el estudio de las sociedades en algunos desarrollos. Estos se han centrado, por un lado, en analizar la interrelación entre los agentes empíricos y sus sociedades por la vía de construir sus perfiles a partir de grandes tipologías socio-psicológicas, las que responderían a formas sociales y culturales específicas, vinculadas, en muchos casos, a procesos de transformación estructural históricamente situados (Riesman, 1981; Marcuse, 1998; Lasch, 1999; Sennett, 2011; Lipovetsky, 2003; Elliott y Lemert, 2006 o Adorno et al., 1965). Por otro lado, con un enfoque muy distinto, se pueden situar trabajos que se basan en adaptaciones sociológicas de categorías psicológicas, como pueden ser el uso de patologías del alma para describir el período actual (Lasch, 1999; Ehrenberg, 2000, 2010; Otero, 2012) o las recientes articulaciones entre psicoanálisis y sociología (ãiãek, 2001; Elliott, 2003). En ellas, el agente empírico ha sido considerado principalmente desde su función expresiva de una época. Son los impactos sobre el carácter, la subjetividad o la personalidad los que constituyen el núcleo de interés para estas posiciones. La cuestión de la agencia y la de las singularidades diferenciales no es incorporada porque ambas caen fuera de la definición del problema. De este modo, la pregunta por el sostén en lo social como un rendimiento activo del agente empírico no tiene espacio para ser siquiera formulada.

Existen, sin embargo, a pesar de ser minoritarios, un conjunto de trabajos, los que, cada uno a su manera, han buscado acercarse a la cuestión de cómo se sostienen los agentes empíricos en la vida social, aunque, como se podrá observar luego, las maneras en que han abordado este asunto puedan ser consideradas parciales. Mencionaremos tres de los más significativos de estos conjuntos aunque, por cierto, no únicos.

Por un lado, las perspectivas socio-psicológicas. Ellos han sido realizados desde la sociología, pero por lo general en diálogo con la psicolo- 
gía, ya sea a través de estudios de socio-análisis (Amrani y Beaud, 2004; Bajoit, 2009), de sociología clínica (Gaulejac, 1987 y 2009; Gaulejac, Hanique y Roche, 2007) o disposicionalistas (Lahire, 2002 y 2004a; Kaufmann, 2001). Estas miradas sociológicas constatan un sinnúmero de "anomalías" o de "disonancias" entre las posiciones sociales objetivas y las orientaciones de los individuos (Lahire, 2004b), ya sea a través de estrategias de incongruencias estatutarias, de ambivalencias normativas o de contradicciones entre hábitos, y ponen el foco sobre ellas. En este sentido, se interesan por las especificidades de las combinatorias individuales. Sin embargo, ellas, a pesar de la complejización y pluralización que aportan, han tendido a privilegiar dimensiones psicológicas y a darle un enorme acento a lo singular en detrimento de dimensiones macro-sociológicas. El trabajo de los individuos no es obviado, pero tiende a ser colocado del lado de lo psíquico o mental, ya sea por mediación de los aportes psicoanalíticos o cognitivistas.

Por otro lado, abordajes desde el interaccionismo. Aquí, aunque el estudio del proceso mismo de producción y de singularización de los individuos quedó relativamente ausente $\mathrm{o}$, al menos, claramente restringido, se encuentra un acento particular en el desempeño del actor. En este marco un aporte especialmente significativo es el de Goffman. Este puede ser leído como un intento de desentrañar las formas en que los actores resuelven el problema de la coordinación a partir de un desempeño de tipo dramatúrgico constante así como de sus habilidades de cara a los marcos de referencia indispensables para hacer inteligibles las situaciones sociales (Goffman, 2006a, 2006b). Aunque el interés del autor está puesto en la (inter)acción, este tiende a restringirse solo a las formas de dramatización efectivas aunque contingentes del rol. La "franja", para retomar el término goffmaniano, por la que se recorta el estudio del trabajo del actor está definida en el contexto de la cuestión de la coordinación y restringida al momento de la interacción (o máximo a su preparación en la "región anterior") (Goffman, 2006a). $\mathrm{El}$ análisis de las formas de sostenerse en lo social, entonces, es reducido a una sola dimensión, la interactiva. Otro límite de este enfoque es que aunque Goffman declarara explícitamente que su perspectiva centrada en el ámbito de las interacciones no implicaba negar el peso de la dimensión estructural, y que incluso intentara desarrollar una reflexión sobre el carácter de esta relación (1983), como no ha dejado de indicarse, no se encuentra en él una consideración consistente y satisfactoria respecto de esta articulación. El trabajo del actor queda 
analíticamente aislado del conjunto de rasgos estructurales de la organización social en la que se desarrolla la interacción. Aunque es posible acercarse a las formas en las que se sostiene en la interacción y su temporalidad limitada, en rigor, de ello no se puede inferir la relación con las dimensiones más estructurales y, por lo tanto, sus significaciones más generales para la comprensión de una sociedad.

Finalmente, una tercera línea es la del sujeto y la subjetivación abierta por Foucault en sus últimos cursos y publicaciones (Foucault, 1999a, 1999b, 2005). En ella el interés anida en las formas en que los individuos resuelven y constituyen la relación de sí a sí a partir de la movilización de técnicas históricamente disponibles. La dimensión individual es incorporada en esta reflexión y, por lo tanto, lo que subyace, por más recortada que sea, es la idea de la existencia de un trabajo del propio individuo en el establecimiento de las formas que toman sus conductas. No obstante, aunque es cierto que por interposición de la cuestión de la ética, un grado de libertad y agencia es atribuida a nivel individual, es indispensable notar que el análisis de estas técnicas y este trabajo es concebido en el marco más general de la cuestión de las formas de dominación, como lo muestra toda la reflexión sobre gubernamentalidad desarrollada paralelamente por el autor (Foucault, 2006), y por lo tanto responde a una concepción que hace equivaler sujeción a subjetivación. En efecto, más que ser expresión de un interés específico por las modalidades concretas y plurales por las que los individuos se sostienen en el mundo social, el interés aquí está centrado en las técnicas históricas a disposición para la construcción de la relación sí a sí, las que no pueden ser leídas sino como parte de los dispositivos históricos de poder, saber o placer. Pero, además de esta dificultad para articular los dos órdenes, una segunda cuestión a notar es que el trabajo del propio agente es concebido exclusivamente en el marco de la producción de la relación de sí a sí. Es decir, reducido a una sola esfera.

Del análisis de estas posiciones, y de sus límites, se desprenden al menos tres orientaciones para enfrentar el estudio de las maneras en que los individuos se sostienen en lo social. En primer lugar, la necesidad de subrayar su vínculo con factores estructurales y en esta medida su significación para la comprensión de las sociedades. En segundo lugar, la importancia de no psicologizar el abordaje, y recuperar los factores sociales y las formas que intervienen en perfilar este rendimiento. En tercer lugar, la conveniencia de restituir la pluralidad de dimensiones 
que el trabajo de sostenerse en lo social comporta (habilidades interaccionales y fórmulas de construcción de relación de sí a sí, por cierto, pero también disponibilidad y movilización de recursos, posibilidad de apegarse a la vida social, entre otras).

En lo que sigue, y tomando en cuenta lo hasta aquí desarrollado, nos detendremos a mostrar y argumentar las definiciones teóricas y conceptuales a partir de las cuales se ha construido el enfoque para abordar el problema de las formas en las que los individuos se sostienen en lo social, cuya ilustración se realizará en la tercera parte de este texto.

\section{EL ESTUDIO DEL TRABAJO DE LOS INDIVIDUOS PARA SOSTENERSE EN LO SOCIAL}

\section{La Relación con lo Estructural}

Como se desprende de lo hasta ahora discutido, el trabajo del individuo para sostenerse en lo social solo es significativo para la sociología si es acompañado por una noción de lo social que conceptúe a los individuos y su agencia como constituyentes primarios de las formas que toma la vida social. Una vía relevante para alcanzar este objetivo, en nuestro caso, ha sido articular este problema a la noción de pruebas o desafíos estructurales, y la concepción de lo social que le subyace desarrollada por Martuccelli (2006, 2010a).

Esta perspectiva, concibe la vida social como un espacio en el que los actores se experimentan como sometidos a un conjunto de desafíos o problemas específicos que deben enfrentar de manera ordinaria y continuada (desde conseguir un trabajo hasta tomar el bus en las mañanas para llegar a él, pasando por tener una pareja o sostener relaciones con los extraños). El carácter de estos desafíos, por cierto puede ser altamente personal (como una pérdida o el desarrollo apasionado de una afición), pero existen algunos de ellos que son transversales y por lo tanto activos para todos los miembros de un conjunto socio-histórico. Según Martuccelli, este tipo de desafíos y las formas específicas que toman en las experiencias individuales deben ser considerados expresivos de los rasgos estructurales que definen a ese conjunto socio-histórico. Es decir, expresivos de los factores que son particularmente pregnantes para las formas que toma la vida social (factores que variarán según las diferentes sociedades: las formas de producción, las reglas que ordenan relaciones con los otros o la organización social del tiempo, etc.). De esta manera, una sociedad puede ser definida por la

DADOS - Revista de Ciências Sociais, Rio de Janeiro, vol. 61, n’ 2, 2018 
naturaleza y la cualidad de los desafíos estructurales que enfrentan sus individuos, porque, en verdad, ellos no son sino la expresión transformada y traducida (pues aunque son comunes se difractan en función de los diferentes contextos de vida) de las dimensiones estructurales (y las expresiones institucionales que las acompañan) que caracterizan aquella sociedad.

Entender la sociedad de esta manera tiene una consecuencia extremadamente importante para nuestros fines: lo social solo puede ser entendido como dotado de elasticidad (Martuccelli, 2005). Lo anterior quiere decir que un margen siempre presente para la acción individual es inherente a la ontología de lo social. El espacio para la acción está dado por la consistencia de lo social mismo. La agencia es un atributo del actor, solo realizable porque ya presente en el conjunto de "lo posible" en lo social. La vida social, partiendo desde aquí, debe ser entendida, entonces, como una interfase, con grados variables de contingencia y determinación, en la que se juega la continuidad, la intermitencia o la discontinuidad de las formas que ella toma.

En consecuencia, ahora en nuestra lectura, un conjunto, comunidad o grupo socio-histórico se define por las pruebas o desafíos estructurales que lo constituyen, cierto, pero, la comprensión cabal de la vida social, y sus transformaciones, solo pueden obtenerse en la medida en que se consideren las maneras en las que ellos son enfrentados, o puesto en otros términos, tomando con todo rigor la consecuencia del carácter elástico de la vida social. De esta manera, y si bien Martuccelli en sus trabajos ha puesto el acento más bien en estudiar esta esfera en los procesos de individuación como focos centrales para inteligir lo social (2006, 2010b; Araujo y Martuccelli, 2012), lo cierto es que esta concepción permite articular la dimensión estructural con lo que es nuestro interés aquí: el estatuto específico de los rendimientos que realizan los individuos para "habitar lo social", es decir para sostenerse a sí mismos en la vida social al enfrentarla.

La articulación teórica con una ontología elástica de lo social permite afirmar este rendimiento de los individuos como un objeto de estudio sociológico por derecho propio. No porque sea un nivel adicional pero importante en el estudio de las sociedades, sino porque esta dimensión, las formas de sostenerse en lo social, lejos de ser secundaria, es inherente y constitutiva, co-partícipe, de lo que hace la armazón misma de una sociedad. En última instancia, es posible colegir, una socie- 
dad no es sus factores estructurales, sino lo que se produce en el interjuego entre lo que estos factores estructurales plantean a los individuos como desafíos ordinarios y las formas ordinarias (y extraordinarias!) en las que ellos se sostienen al enfrentarla.

Planteado de esta manera, el estudio de las formas de sostenerse en lo social no puede leerse como un enfoque intimista o psicologista, sino como una manera de acercarse a las exigencias estructurales que presenta una sociedad, y especialmente a sus consecuencias, pero, sobre todo, como una vía para emprender un tipo de análisis que entrega una visión procesual de los caminos que, por intermediación de los rendimientos de sus agentes empíricos, va tomando de manera gradual y contingente esta sociedad.

\section{Una Definición Sociológica}

La segunda gran exigencia al abordar este problema, es establecer una definición sociológica operacional de lo que implica sostenerse en lo social y de los procesos que lo componen. Para producirla, nos hemos apoyado no solo en los resultados de la investigación empírica que subyacen a este texto sino en la elaboración de resultados anteriores (Araujo, 2009a y b).

Es posible, sobre esta base, designar al trabajo para sostenerse en lo social, como el conjunto de rendimientos necesarios para cumplir con las tareas de preservarse, soportar, apegarse, y orientarse en la vida social. Para decirlo de otra manera, y como nuestros resultados lo mostraron, las personas de cara a los desafíos estructurales que enfrentan deben desarrollar caminos para poder sustentarse y darse continuidad material y subjetiva; para tolerar y/o remontar las presiones y apremios que la vida social implica; para mantener la motivación, la "creencia" o la "ilusión en el juego", para tomar prestados términos de Weber y Bourdieu; $y$, finalmente, para orientarse en las maneras en que transitan la vida social.

Este es un quehacer que se constituye en el entramado de los desafíos estructurales que se enfrentan ordinariamente, y que puede ser observado simultáneamente desde la perspectiva de las respuestas prácticas al mundo y desde las operaciones que se desarrollan en la economía subjetiva. 
Son tres los factores intervinientes que sirven de insumos para las formas en que se resuelven o definen los caminos que toman los individuos para sostenerse en lo social:

a) Los ideales que se encuentran socialmente a disposición y, en particular, aquellos que han alcanzado su inscripción en los individuos (Araujo, 2009a). Los ideales sociales son elementos colocados en el régimen de lo deseable ofertados a la identificación para los sujetos en los discursos y representaciones sociales, los que aportan a las formas de orientación, legitimación y representación de sí, pero solo en cuanto inscritos como Ideal del Yo, es decir dotados de fuerza compulsiva y de fuerza libidinal de apego (Freud, 1974; i ek, 1992: 147).

b) El "saber-hacer" en lo social que resulta como decantado de las continuadas y reiteradas experiencias sociales que se enfrentan. La decantación de estas experiencias produce un saber sobre lo social que interviene orientando las relaciones del individuo con el mundo y sus formas de hacer en él. Se trata de un saber sobre las lógicas que gobiernan las interacciones en la vida social, que tiene el poder de influir en la orientación de la acción porque informan sobre las formas eficientes de conducción en el mundo. Es decir, entregan insumos de racionalidad práctica para la acción (Araujo, 2009b).

c) El entramado de apoyos materiales, afectivo-emocionales, prácticos y estatutarios con los que se cuenta o se es capaz virtualmente de movilizar, y que funcionan como soportes, es decir como recursos, pero en cuanto ellos han cobrado una particular significación para el individuo (Martuccelli, 2007) en el marco de la tarea de enfrentar los desafíos societales y sostenerse en la vida social.

Ellos, participan, en el marco de configuraciones plurales, en las formas de orientación de la acción, representación y legitimación de los individuos en el mundo social, como ya lo mostraron los resultados de investigaciones, por ejemplo, respecto del principio normativo de igualdad o al ideal de derecho en su encuentro con el conjunto de las experiencias sociales para el caso de Chile (Araujo, 2013).

Pero, si estos factores participan, en combinaciones múltiples, en forma simultánea y continua en dar forma a las modalidades en que se enfrenta lo social, nuestra investigación actual ha mostrado que algunos de estos ideales, experiencias o soportes, o más generalmente algunas de sus combinaciones, cumplen una función particularmente destaca- 
da en el sostén de cada cual en lo social, pues actúan entregando consistencia y estabilidad a las formas de estar y hacer en el mundo social y de vincularse con él. Se constituyen como anclajes socio-existenciales.

Los anclajes socio-existenciales pueden tener la función de apegarnos a la vida social, de permitirnos soportarla, o de entregarnos los insumos materiales o emocionales necesarios para enfrentar los desafíos que se nos presentan, para poner solo algunos ejemplos. Ellos, pueden, por otro lado, tomar la forma de proyectos o de sueños; de fuga, ilusión o mala fe (en el sentido sartreano de auto-engaño), entre otros. Es decir, son múltiples. Pero esta pluralidad no es infinita, porque ellos no son ni exclusiva ni principalmente productos subjetivos de una individualidad, aunque cumplan un papel central en las existencias sociales particulares. Los anclajes socio-existenciales son productos histórico-societales, de uso colectivo, socialmente operantes e individualmente activos.

En efecto, es imposible pensar que ellos puedan constituirse fuera de determinadas coyunturas históricas y estructurales, pues cumplir la tarea de estabilización y de aportar consistencia a las formas de sostenerse en lo social depende de manera directa del tipo de desafíos de tipo estructural que de manera ordinaria se deben enfrentar. Un anclaje socio-existencial es capaz de cumplir su papel solo en cuanto apuntala a los individuos en las respuestas a aquello que en sus existencias efectivamente deben afrontar. Su carácter histórico resulta, pues, evidente: dependen, al menos parcialmente, de las figuras que toman los rasgos estructurales que definen una sociedad en cada momento histórico. Por ejemplo, si el acervo de tradiciones históricamente transmitidas de una comunidad puede haber funcionado como un anclaje socio-existencial en ciertos momentos históricos, no es plausible que lo haga en sociedades que exigen de sus miembros respuestas flexibles y novedosas.

Por otro lado, en su camino de expansión en la sociedad, estos anclajes se declinan en función de las condiciones concretas de las existencias sociales propias de los diferentes grupos sociales (sectores sociales, género, edad, etc.). Pongamos, como ejemplo, las redes de relaciones sociales. Estas se constituyen en un anclaje socio-existencial debido a la importancia en Chile de la actuación de factores informales para acceder a las oportunidades que la sociedad ofrece (Barozet, 2006; Núñez y Gutiérrez, 2004; Araujo y Martuccelli, 2012). Pero, como lo muestra 
nuestro trabajo, existen diferencias en los modos en que este anclaje se cristaliza en el caso, por ejemplo, de los sectores más acomodados, en razón de su cercanía a círculos de poder, ya sea gracias a sus relaciones familiares o a los contactos obtenidos a lo largo de su vida educativa, respecto de los sectores populares en los que la cercanía a círculos de influencia y poder es menor. Si en el primero, el contenido de "redes" es un conjunto de relaciones históricas con cierta permanencia y capacidad de proliferación, en los segundos, el contenido de "redes" es un conjunto más contingente, más frágil y más actual de relaciones.

Finalmente, los anclajes socio-existenciales son activos y visibles a nivel individual. En estos casos, a pesar de su carácter colectivo, compartido, ellos aparecen en el contexto de retóricas altamente personalizadas y adoptando formas singulares de acuerdo a la topología y dinámica subjetiva de cada caso particular.

En el próximo apartado intentaré mostrar lo antes argumentado a partir de los resultados de la investigación empírica arriba descrita. Me concentraré en un tipo de anclajes existenciales, las expectativas de futuro, a partir de una sola de las figuras que toma en el caso de Chile: el sur-campo ${ }^{2}$. Me interesa mostrar en la exposición, su presencia transversal, su aporte múltiple a las tareas de sostenerse en lo social, su estrecha relación con los desafíos estructurales que caracterizan a esta sociedad, y, por tanto, su carácter inextricablemente histórico-societal, social y subjetivo.

\section{LA EXPECTATIVA DE FUTURO COMO ANCLAJE SOCIO-EXISTENCIAL}

Nuestro trabajo mostró una cuestión, quizás evidente y simple, pero no por ello menos importante. Puso en evidencia que sostenerse en la vida social requiere, entre otros, un tipo de trabajo particular: mantener viva la esperanza de un potencial cambio en las situaciones que pueden ser consideradas como indeseadas o incluso vividas como críticas por los individuos, o sea, producir expectativas, deseables, de futuro. Ya sea a manera de fuga, de contrapeso o de transformación de la situación presente, este tipo de trabajo provee a los individuos de las grandes o pequeñas alegrías, de las esperanzas, de la orientación para sus actos, o de las motivaciones necesarias para afrontar los desafíos cotidianos. Por supuesto, estas expectativas de futuro pueden presentarse en formulaciones más cercanas a los sueños que a los proyectos, $\mathrm{o}$ exactamente a la inversa, pero lo importante es que sea cual sea su esta- 
tuto, y a pesar de que no es menor esta diferencia, ellas funcionan como anclas para la existencia social.

Las expectativas de futuro en cuanto anclaje tienen como función hacer soportable lo insoportable de la existencia, como Freud lo propuso, dando como ejemplo a la religión, las drogas o el amor (Freud, 1999). Le dan forma a un futuro más auspicioso $\mathrm{y}$, así, abren una ventana de posibilidades y de alivio. En este sentido, funcionan como un paliativo a los "malestares de la cultura" y aportan, vía la esperanza difusa o el proyecto, a las maneras en que uno se sostiene en lo social.

Pero, las expectativas de futuro, funcionan como anclas también porque revelan y ponen en acción de manera explícita, y eso las hace especialmente interesantes, lo que Koselleck ha llamado el "horizonte de expectativas" de una época. Es decir, la presencia del futuro en el presente, lo que apunta a lo no experimentado, lo que no puede confirmarse, y no tiene garantía de realizarse, pero que tiene una función performativa respecto al presente y a los trayectos posibles (1993:338-341). Desde esta perspectiva, funcionan como una clave de interpretación a la vez emocional y racional del tiempo presente.

En consecuencia, las expectativas de futuro gracias a su doble función de futuro en el presente y de paliativo, aportan a las formas de sostenerse en lo social dándoles consistencia y, aunque es verdad que en medidas muy variables, a darles estabilidad a las existencias sociales. Por el otro, y esta vez desde un nivel analítico, ellas se constituyen en una vía privilegiada para acceder al conjunto de factores estructurales que aparecen como los más pregnantes para la definición del trayecto de los individuos pero, también, aquellos factores cuyos desafíos son los más difíciles de enfrentar y soportar en el presente.

En este texto vamos a detenernos, como ya lo hemos anunciado, en solo uno de estos tipos de anclajes existenciales en obra en la sociedad chilena: "el Sur-el Campo".

\section{El Sur-Campo}

Simmel (2001), en su famoso ensayo sobre las grandes ciudades, sostenía que una de las consecuencias más importantes de la condición moderna era que los individuos desbordados por el exceso de estimulación que las metrópolis les imponían, terminaban afectados por un estado de hastío, de indiferencia, por una actitud de reserva y de inte- 
Kathya Araujo

lectualización en su relación con el mundo, y por un esfuerzo constante de singularización. Una respuesta, pensaba el autor, que resultaba inevitable dados los límites fisiológicos propios de las personas, cuyo sistema nervioso no poseía la capacidad de responder a este alocado ritmo de estímulos, y que resultaba comprensible en el contexto de la lucha por mantener su autonomía e individualidad frente a la amenaza que planteaba el mundo objetivo en razón de sus rasgos estructurales.

La ciudad parece tener una valencia análoga para los individuos en la sociedad chilena hoy. La vida en ella es percibida como plagada de demandas excesivas y vivencias desagradables, una "tortura" o un "suplicio" dirá Cristián, un profesional de sectores medios (SM) en la cincuentena. Pero, sin duda, las reacciones a ello así como las maneras en que se entienden y significan estas experiencias no pueden ser asimiladas a lo que entrega el análisis simmeliano. Para empezar, y con seguridad, con mucha más claridad que los contemporáneos de Simmel, los individuos en Chile tienen una clara consciencia de que, en última instancia, la vida en la ciudad no es sino el escenario privilegiado y la expresión concentrada de las exigencias estructurales de la condición histórica que es la suya, y exhiben sofisticadas interpretaciones de las mismas. Desde aquí, para los individuos estudiados la ciudad es la ciudad, por supuesto, pero la ciudad es, por sobre todo, la encarnación de la sociedad en la que les toca vivir.

Una segunda diferencia importante es que la respuesta principal para enfrentar esta exigencia percibida como desmedida para con ellos, no es el sentimiento de hastío e indiferencia, una retracción y un trabajo de singularización, como lo suponía el autor arriba citado, sino la búsqueda de elementos que sostengan la ilusión y posibilidad de poder protegerse o revertir en sus vidas personales las consecuencias que consideran negativas de estas exigencias estructurales. La fórmula más importante, masiva y transversal: mantener la expectativa de futuro, sea como vago anhelo o proyecto, de dejar la ciudad e irse al sur o al campo. En contra de lo que planteaba Simmel, más que una respuesta de acomodamiento a las exigencias de la condición actual, así, ello puede ser leído como una vía para sostenerse en la vida social por medio de la esperanza en la existencia de un espacio físico otro en el que estilos de vida menos amenazantes y erosivos pudieran realizarse, un espacio en cuya constitución la imaginería sur-campo, juega un papel principal. 
Armando, un maestro de cocina de los sectores populares (SP) de 38 años, lo expresa con vehemencia. Interrogado por qué consejo le daría a alguien que viene de fuera para facilitar su vida en $\mathrm{Chile}^{3}$, responde riendo que le diría "que se devuelva (...) porque está la cagá en todos lados (en Chile)". Sobre todo, le diría, sostiene, que de vivir aquí no debiera hacerlo en "esta porquería de Santiago". Lo mismo opina Oriana, trabajadora de un hospital y madre, separada, de 4 hijos. Al menos, cree ella, debería intentar "no quedarse en Santiago" y tratar de ir al campo. Esta perspectiva atraviesa a todos los sectores sociales. Pero, y esto es lo importante, ella es reveladora no solo de las opiniones respecto de la vida en las ciudades y de las miradas ideales acerca de las zonas más rurales sino de la manera en que se construyen las proyecciones ideales a futuro. Marcelo, un mediano empresario exitoso en la cuarentena, le aconsejaría a este extranjero ir a una isla a los canales del sur, donde no lo "huevée" nadie... De hecho, él y su pareja están pensando en hacerlo...quieren ir al sur "a alguna parte donde tengamos campo, tranquilos, solos, en nuestro mundo".

Es en este espacio, siempre el mismo pero nominado como "campo" o "sur", según los casos, en el que se deposita la esperanza de una "buena" vida.

Pero, ¿qué es una buena vida? La expectativa futura de irse de la ciudad, es correlativa del -también transversal- más importante e íntimo deseo para sí mismos: contar con tranquilidad. Sentimiento de paz y tranquilidad que se presenta, con mucha frecuencia, como el significado de la felicidad para los individuos en la sociedad chilena. Vivir en paz y vivir en tranquilidad son deseos, que, a contraluz, permiten entrever las experiencias de presión, intranquilidad, y alta demanda que experimentan en la ciudad, $\mathrm{o}$, más precisamente, en la sociedad en que viven. "Me gustaría terminar mis días en silencio", "en un lugar en la naturaleza", dice Silvano, un hombre de 35 años de los sectores populares, a quien le gustaría "poder tener la capacidad de establecer una mejor relación con otras personas" y poder tener alguna actividad que le permitiera "sentir un pequeño y humilde desarrollo personal, humano". Por eso, esperaría poder mudarse a una zona rural o a una playa...

Estar tranquilo quiere decir dos cosas a la vez. Por un lado, una vida menos exigente en términos de requerimientos económicos, exigencias de consumo de bienes y de tiempo. Cristián un investigador y pro- 
Kathya Araujo

fesor universitario de 47 años bien establecido en el área de las ciencias naturales, y quien tiene claro que va a irse de Santiago llevando a sus hijos en algún momento, lo pone de esta manera:

¿para qué mierda estoy metido acá? Tengo compañeros de colegio que viven autosustentados, no sé si yo vaya a hacer eso, pero son personajes que tienen hijos de la misma edad de los míos, que viven con sus señoras en el campo, que no es ni de ellos (...) comen de lo que plantan y a sus hijos los crían ellos, los educan ellos, y para lo único que tienen luz, con estas cuestiones solares, es para conectarse una vez a la semana a internet y para sus celulares.

Lo que se revela en este testimonio, representativo de la gran mayoría, es lo que aparece como especialmente insoportable en la vida social: la cuestión del dinero que, se haga lo que se haga, no alcanza; la del empuje al consumo que no coincide con las posibilidades reales de las personas; y la de la exigencia en términos de tiempo que anula los tiempos propios. En breve, los costos que se imponen en términos personales tanto para no ser expulsado por el mundo del trabajo como para poder mantener un lugar en lo social.

Por el otro, tranquilidad supone llevar una vida en la que uno no esté enfrentado a la necesidad de ser competitivo, agresivo e indiferente, $y$, de manera inversa, de tener que lidiar con este tipo de experiencias en el encuentro cotidiano con los otros. Desde la delincuencia y la droga, omnipresente en los relatos de los sectores populares, hasta las experiencias en el metro abarrotado, pasando por los cotidianos rostros de disgusto y enojo con los que deben lidiar en los ambientes laborales o siendo atendidos en un café, las interacciones son percibidas como irritadas. Como señala Antonio (SM), "con quien hablas está estresado, y claro que está estresado, si se demora en llegar a su trabajo en la locomoción y se demora en llegar a su casa", y además, agrega, "es una sociedad muy competitiva". La tranquilidad es la expectativa que surge de la experiencia de una sociedad que exige de cada cual, por tanto, un grado alto de alerta, competitividad y de agresividad... o, en su defecto, de estrategias constantes de repliegue hacia las "zonas de seguridad" (no cambiar los trayectos conocidos, quedarse en la casa todo lo posible, o dejar de ir a mirar vitrinas al centro de la ciudad por lo desagradable que puede llegar a ser la conducta de las personas que se cruzan). Una vida tranquila es concebida como una vida en donde la amabilidad y la humanidad básica puedan ser recuperadas, y es precisamente en el campo donde ella se podría encontrar. Como dice 
Oriana (SP), "la sencillez de las personas, la humildad de la gente, porque yo sé que es difícil en Santiago a veces encontrar la sencillez, la humildad", o como es visible en el caso de Pedro (SM, habitante de una ciudad costera de provincia), quien considera que en el campo no hay tanta necesidad de "cuidarse" las espaldas porque allí está la "verdadera gente", dice, aquella que es menos envidiosa, más feliz, más cariñosa, más receptiva, aunque sea más pobre.

El sur-campo, funciona como un anclaje socio-existencial porque sustenta la esperanza y organiza las proyecciones, pero al mismo tiempo porque funciona como un instrumento que, en contraste con el futuro imaginado, permite dar significado al presente. Compartido por la mayoría aparece en la forma de la honda confesión del sueño más propio. El anclaje socio-existencial que se revela como un elemento colectivo, es vivido como profundamente íntimo y personal.

\section{Un Más allá del "Sistema"}

Es importante hacer notar que los entrevistados que viven en las otras ciudades más pequeñas que Santiago también expresan juicios críticos respecto de las exigencias que pone la vida social, y que la idea de dejarlas en beneficio de una vida en zonas más protegidas (rurales) está también presente. Sin embargo, también es indispensable reconocer que estas críticas aminoran en la medida en que sus ciudades sean comparadas con Santiago, o cuando, en general, se comparan con ciudades más grandes o consideradas como más insertas en el "sistema". Los criterios de comparación están dados, así, por la mayor o menor concentración expresiva del "sistema" en ellas.

Salir de la ciudad debe entenderse, en rigor, como intentar salir del "sistema" o del "modelo", una denominación muy extendida y muy presente en los discursos críticos sobre la sociedad (Araujo y Martuccelli, 2012). Las críticas apelan a la consolidación de un capitalismo que perciben como incontrolado y desigual. Este "sistema" se encarna en diferentes experiencias. Por un lado, en la imprevisibilidad de un mercado laboral de exigencias desmesuradas y de retribuciones escasas tanto en seguridad como salariales. Experiencias extendidas en una realidad en la que solo un $41,6 \%$ del total de ocupados y un $56 \%$ de los asalariados presentan un empleo protegido, vale decir, con contrato escrito, indefinido, liquidación de sueldo y cotizaciones para pensión, salud y seguro de desempleo (Fundación Sol, 2014:5); en la 
que el $80 \%$ del empleo asalariado es de baja calidad, pues no se encuentra protegido e implica ingresos menores a dos sueldos mínimos, lo que es considerado como el Ingreso Ético Mínimo (Stecher y Godoy, 2014:56); y en la que se ha desarrollado en las últimas décadas una significativa intensificación del trabajo, presiones elevadas derivadas de la aceleración de los procesos de producción, la extensión de las horas de trabajo ${ }^{4}$ y el consecuente alargamiento de jornadas (Ramos, 2009). A ello necesariamente hay que sumarle, en el caso de Santiago, el elevado número de horas de traslado que en promedio deben ocupar para trasladarse de sus hogares a sus centros de trabajo y viceversa: más de dos horas por día en promedio, lo que aumenta claramente para quienes habitan las zonas periféricas y menos favorecidas de la ciudad (INE, 2009).

Por otro lado, se encarna en un "sistema" que los empuja a la avidez y la insaciabilidad, fundamentos del consumo, que los torna enemigos de la mesura, y que los encadena a través de un alto nivel de endeudamiento (Banco Central de Chile, 2010; Barros, 2009), el que no es solo resultado de un acrecentado consumismo, sino también de una limitada capacidad de los salarios para cubrir las necesidades que consideran básicas. Una cuestión que concuerda con lo que muestran los datos oficiales. En efecto, según la Encuesta Financiera de Hogares, entre el 2011-2012, 68\% de los hogares chilenos poseía algún tipo de deuda con una ratio de deuda sobre ingreso de $74,6 \%$ para el total de hogares, sin grandes variaciones entre sectores socioeconómicos. Los hogares destinan entre $45 \%$ de sus ingresos mensuales (entre los de mayores ingresos) para el pago de sus deudas (principalmente hipotecarias) y 25,4\% para los hogares de menos recursos (en deudas de consumo especialmente con casas comerciales) (Banco Central de Chile, 2013). El estrés financiero al que están expuestos es muy significativo, una cuestión que se agudiza en los sectores de menores recursos, los que habitualmente pagan tasas de interés más altas por tratarse de deudores más riesgosos (Echeverría, 2015).

Igualmente, se trata de un "sistema" que los pone en tensión respecto al conjunto de valores sociales, morales y de sociabilidad que al mismo tiempo ellos reconocen como importantes para sí. Es decir, que los enfrenta a contradicciones de manera constante y reiterada con las formas ideales de sujeto que imaginan que deberían encarnar. Los pone en tensión porque cumplir con los estándares de éxito que él propone aparece como virtualmente imposible dado lo desmedido de los 
mismos y las pocas oportunidades reales de mejora que se les ofrecen. O porque los destina a la inautenticidad debido a lo que se supone que son sus deberes en el "reinado de la apariencia" que lo caracteriza, una cuestión especialmente importante para los sectores medios, que han hecho suyo el valor de la autenticidad (Méndez, 2008, 2009). O, todavía más, porque excluye de su horizonte principios de espiritualidad, consideraciones no economicistas y, sobre todo, una definición ética respecto a la relación con los otros. En efecto, según una encuesta de caracterización de la estructura social en la Región Metropolitana, el 79,7\% está de acuerdo en que el sistema económico lleva a competir haciendo más difícil el afecto y la solidaridad entre las personas (Mayol, Azócar y Azócar, 2013).

El referente común, el "sistema", por cierto, es el conjunto de transformaciones percibidas que ha impulsado la instalación de un modelo económico y societal desde hace alrededor de cuatro décadas, que se agrupa genéricamente bajo la noción de neoliberalismo (Harvey, 2007). Resulta indispensable subrayar que las visiones negativas sobre sus implicancias para la vida social y las esperanzas de "salida" no son exclusivas de quienes se oponen al modelo económico. Aún estando de acuerdo con él, el reconocimiento de la magnitud de los costos personales, familiares y sociales es transversal y la sanción crítica aparece inevitablemente.

Las corrientes subterráneas que subtienden y son motor de las expectativas de futuro que estamos en tren de analizar, entonces, son la asfixia, el desgaste y la presión que produce tener que vivir, bajo modalidades distintas, dentro del "sistema", es decir, para ponerlo en palabras de Miguel (SP), un mecánico, dejar de llevar una vida que es "sufrida" que "no tiene ningún brillo" y donde "no hay futuro". El anclaje socio-existencial se devela en su íntimo vínculo con los rasgos estructurales de una sociedad.

\section{Las Transformaciones de una Geografía}

Sur o Campo, aparecen, pues, como dos nombres para un mismo espacio: son los nombres que de manera privilegiada toma el espacio utópico a ser alcanzado en el futuro y que está destinado a salvarnos de las exigencias desmedidas que nos pone la sociedad en este momento histórico. 
Las denominaciones dadas a este espacio son diferenciales según sector social, como veremos, el sur para los sectores más acomodados, el campo para los de menores recursos. En cualquiera de los casos, se trata siempre de la movilización de una imagen idealizada de lo rural contra lo urbano. Pero, como las citas lo dejan entrever, se trata de una idealización en un contexto histórico en el que lo urbano ya no es el equivalente de una modernidad y un progreso que amenaza, como ha sido discutido especialmente en los debates de los inicios del siglo XX, sino que ahora, celebrando con tranquilidad la modernidad y el progreso, este es, sin embargo, convertido semánticamente en el depósito de los desafíos estructurales más exigentes. En este marco, lo no urbano o lo "menos" urbano (una ciudad más chica, por ejemplo) se asocia con la imagen de un espacio liberado de estas exigencias o, al menos, con la potencialidad de permitir de alguna manera vadearlas. De hecho, las personas pueden gustar de sus ciudades, valorar las ofertas en cultura, las ventajas en salud o en educación, las comodidades que ofrecen, pero a fin de cuentas, todos estos aspectos se ven opacados por los rasgos que toma la dinámica de la vida social en ellas.

Si es cierto que, como ha sido discutido, esta imaginería de lo rural es, históricamente, un elemento destacado en la sociedad chilena (Bengoa, 2009; Márquez, 2003, 2012), también lo es que ella tiene un contenido distinto hoy ${ }^{5}$. No debe entenderse ya puramente como una expresión de la pervivencia del pasado sino que es una expresión de las expectativas de futuro. Con el sur o el campo, no solamente se tramita una nostalgia por los orígenes, posibilitada por una débil crítica y poco distanciamiento con la "barbarie agraria", lo que habría impedido la ciudadanización de la población, como lo ha planteado Bengoa (2009). Lo que aquí se vehicula, hoy, es un espacio que puesto en la línea del horizonte se presta para la construcción de un mundo diferente. Por supuesto, se trata de un espacio percibido como de re-encuentro con ciertas sociabilidades, ciertas temporalidades, ciertas prácticas, y en este sentido se puede considerar con razón que existe una dimensión de idealización en juego. Sin embargo, lo esencial, reside, en particular para los sectores medios y los más jóvenes, en que este aparece como un espacio al que no se llega para ocuparlo de manera pasiva y acomodándose a él, sino para, de manera activa, hacerlo el escenario de un anhelado estilo de vida - en el sentido más profundo del término - que resulta imposible en la ciudad. Es el escenario para tener una vida menos descomunalmente exigida, especialmente en los sectores populares pero no solo para ellos, y en ese sentido, el campo/el sur es percibi- 
do como un antídoto para el cansancio y una rutina desgastante. Es el lugar para llevar una vida con más realizaciones personales, o sea, más sintonizada con uno mismo y con formas más dulcificadas de sociabilidad así como con más posibilidades de desarrollar, disfrutándola, la vida de pareja y / o familiar, (especialmente en los sectores medios, en particular los más jóvenes). Adicionalmente, y esto no es menor, la expectativa de futuro de este espacio geográfico da cuenta de un tipo de estrategia de índole individual que puede ser leída como expresión de los procesos de expansión del individualismo a los que asiste esta sociedad en la actualidad. El carácter societal-histórico del anclaje existencial se muestra en toda su complejidad.

\section{Las Versiones de una Expectativa}

Por supuesto, hay diferencias importantes en las dos maneras de pensar el abandono de lo urbano, en cuanto condensado de las exigencias estructurales actuales, el Sur de los sectores medios o el "campo" de los sectores populares. Estas diferencias de nominación son teóricamente muy significativas porque cristalizan las vicisitudes que toma la expectativa de futuro en el encuentro con las condiciones concretas de existencia de los diferentes sectores sociales, tanto en términos de los recursos con los que cuentan como de sus experiencias sociales.

El "campo" de los sectores populares, dadas las menores oportunidades y posibilidades financieras en este grupo, es un proyecto propiamente de salida. Roxana (SP) y su marido han comprado un terreno en el campo y han construido una casa a la que irán a vivir apenas el menor de sus hijos termine de estudiar. Es para ellos el lugar del retiro final. Para Julia, una operaria de 45 años, separada y con dos hijos a su cargo, "salir" es solo una experiencia transitoria, y no está contemplada dentro de sus posibilidades ahora, pero para ella estar fuera está connotado como la única posibilidad de descanso, de contacto consigo misma y con otros, y de, finalmente, tener un respiro de una vida estricta y rígidamente gobernada por los horarios que le impone cumplir con todas sus obligaciones sin mayores apoyos. Constituye, pues, una intervención dramática sobre la conflictiva relación que sostiene con el tiempo de manera ordinaria. En breve, el campo es para ella, como para la mayoría de los de este sector social, un sueño y un lugar para refugiarse, cierto, pero en el que lo esencial es que es imaginado o vivido no solo como un resguardo sino como depositario virtual del cambio y

DADOS - Revista de Ciências Sociais, Rio de Janeiro, vol. 61, n’ 2, 2018 
de las formas de estar en el mundo. Una posibilidad de desplegar una forma de subjetividad otra.

El "sur", en cambio, en cuanto movilizado por los sectores de mayores recursos, es un proyecto de re-inicio bajo nuevas condiciones. Mariana, una trabajadora por cuenta propia de 50 años, y su pareja planean en cinco años ir a la Patagonia para poner un negocio de turismo; para Diana una terapeuta ocupacional de 34, tomará bastante más años, pero han forjado ella y su compañero la idea de desarrollar un proyecto de cultivos orgánicos lejos de Santiago... y la lista continúa largamente. A pesar de sus muy diferentes historias, todos ellos creen que eso les permitirá dejar atrás una vida llena de incertidumbre por la posibilidad de perder el trabajo, de las penurias económicas de una ciudad cara que cultiva la pretensión consumista y de las exigencias de inversión temporal que no les permiten disfrutar de lo que tienen, especialmente, en términos emocionales y afectivos. Un cambio que exige, lo saben, la adopción de otras formas de vida, más naturales, más lentas, más trabajadas, quizás, pero más gratas. Sobre todo, claro, tener más tiempo para sí y sus otros significativos. Este carácter de re-inicio bajo nuevas condiciones es visible en el juicio que hace Antonio. Aún cuando sabe que él no podrá hacerlo porque ya es muy tarde a sus 55 años y porque debe reconocerse a estas alturas esencialmente como un citadino, él percibe, y aprecia positivamente, que haya grupos, si bien no demasiado numerosos aún, "que se están yendo a vivir a pueblos, se van de la ciudad, no quieren ser citadinos, quieren hacer un cambio partiendo por el cambio de sus vidas".

Como es evidente, el diferencial de los recursos a disposición, y la confianza en que se puede siempre re-comenzar devenida de experiencias sociales menos afectadas por la precariedad y la fragilidad, conducen en los sectores medios a que este espacio utópico en el que otra vida y otro "yo" serían posibles, anhelado por todos, se constituya con más frecuencia en un proyecto que en un sueño, y que este contemple formas más activas de transformación del propio espacio. Las experiencias sociales y los recursos a mano contribuyen a darle un contenido al Sur-Campo, en cuanto expectativa de futuro. Las declinaciones diferenciales y el carácter social de los anclajes-socioexistenciales se ponen de manifiesto. 
En síntesis, el sur-campo se constituye en un auténtico anclaje socioexistencial para los individuos en la sociedad chilena. Al sostener la esperanza de un mundo transformado, hace más soportable la vida ordinaria, y, en su acción sobre el presente, gracias a su capacidad de abrir horizontes y establecer una imagen más amable de sí, es capaz de entregar cuotas de consistencia y estabilidad a los trayectos de los individuos. Como todo anclaje socio-existencial, siendo vivido como parte de los sueños más íntimos y personales, se revela, sin embargo, como una herramienta de uso colectivo para hacer frente a los desafíos estructurales que encaran y para darse orientación, preservarse subjetivamente y soportar la existencia social.

El sur-campo es una ilustración, como existen muchas otras, de la dimensión del trabajo de sostenimiento de los individuos en lo social, un aspecto escasamente reconocido por los estudios en las ciencias sociales y cuya importancia y pertinencia este artículo ha buscado argumentar. El mismo se revela como un tipo de rendimiento de los individuos que debe ser considerado como objeto sociológico por derecho propio, pues es respuesta a las exigencias estructurales de la vida social, se despliega extrayendo y haciendo uso activo de factores y recursos que se encuentran a disposición socialmente y participa en dar forma a la vida social misma. En este sentido, y como lo hemos argumentado, lejos de suponer un enfoque que pone el acento en la singularidad y pluralidad individual, anima a desarrollar una perspectiva analítica que implica poner atención a los patrones colectivos de estos rendimientos, a su vínculo con aquello que histórica y estructuralmente explica su existencia, y a lo que las formas que toman estos rendimientos dicen sobre las sociedades en las que se despliegan y sobre los individuos que las habitan. En breve, es una vía privilegiada para abordar la pregunta por la cualidad y carácter del lazo social en una sociedad. Una cuestión cuya urgencia no ha dejado de ser señalada desde el comienzo de la disciplina sociológica y que se ha constituido hoy por hoy en uno de los desafíos más importantes de las sociedades en las que transcurre nuestra existencia social.

Submetido em 18 de julho de 2016 Aprovado em 26 de março de 2018 


\section{Kathya Araujo}

\section{NOTAS}

1. Proyecto Fondecyt № 1140055. La investigación empírica sobre la que se sostiene este texto estuvo destinada a estudiar la cuestión de los rendimientos de los individuos frente a los desafíos estructurales y se desarrolló entre 2014 y 2017. Consistió en la aplicación de entrevistas en profundidad a 48 hombres y mujeres de entre 30 y 55 años de los sectores medios y sectores populares en las tres zonas urbanas más pobladas de Chile: Santiago en la Región Metropolitana, Concepción en la Región del Bío Bío, y Valparaíso y Viña del Mar en la Región de Valparaíso. Las entrevistas estuvieron destinadas a indagar principalmente: 1) las coordenadas biográficas más importantes de las personas entrevistadas; 2 ) sus percepciones y juicios sobre la sociedad en la que viven y sus estrategias para vivir en ella; 3 ) los momentos especialmente difíciles en sus vidas y las maneras y factores que aportaron a enfrentarlos; 4) las formas de presentación de sí y sus costumbres; 5) el conjunto de sus anhelos y sueños. De otra parte, en las entrevistas se solicitó a las personas entrevistadas que realizaran, primero, un dibujo que graficara la manera en que ellos se veían a sí mismos en el mundo social. Luego de desarrollar una conversación en torno al primer dibujo en el que se les pidió que explicitaran lo que habían hecho, las razones por las que lo habían hecho y sus reflexiones sobre lo representado, se les solicitó un segundo dibujo. Se les pidió, entonces, que hicieran una representación de sí mismos en su intimidad. Respecto de este dibujo se siguió el mismo procedimiento de conversación que con el primero. Con respecto a esto último, vale la pena subrayar que en ningún caso este material fue utilizado, como en el caso de los procedimientos clínicos psicológicos, como material proyectivo a interpretar. Los dibujos solicitados tuvieron la finalidad de ofrecer otra modalidad expresiva, la que tiene la ventaja que al ser una representación espacial en un solo plano ofrece, a diferencia de la comunicación verbal, una representación sintética dotada de simultaneidad. Ellos fueron utilizados con el objetivo de que sirvieran como punto de partida para la conversación que acompañó o continuó esta actividad. Adicionalmente, este artículo se ha beneficiado, en la etapa de su revisión, de las reflexiones y primeras elaboraciones de un proyecto de investigación sobre individualismo en América del Sur, Fondecyt № 1180338. Finalmente, agradezco a quienes evaluaron este texto por sus pertinentes y sugerentes comentarios.

2. Las expectativas de futuro no son el único tipo de anclajes socio-existenciales, existen otros que se sitúan en el campo de la relación de sí a sí, o de las relaciones con los otros, para mencionar solo dos. Adicionalmente, en lo relativo a las expectativas de futuro, en el caso de Chile, se encuentra otra modalidad: el proyecto del trabajo independiente. Sin embargo, decidimos presentar el caso del sur/campo, porque aparece de lejos como el más extendido y transversal de este tipo de anclajes socio-existenciales.

3. La pregunta que fue hecha en todas las entrevistas fue textualmente: "si un extraterrestre viniera a vivir a Chile, ¿qué consejo le darías para facilitarle su vida en Chile?" La pregunta se hizo con el objetivo de indagar las estrategias que consideraban exitosas a la hora de enfrentar los desafíos societales. La formulación en términos inverosímiles produj o un efecto jocoso y abrió a respuestas muy espontáneas y cargadas emocionalmente. 
4. Para 2013 , la OCDE reportó en Chile 2015 horas trabajadas por año y trabajador. Muy a distancia de las 1489 de Francia o las 1388 de Alemania (OECD, 2015).

5. A falta de un estudio específico, es imposible determinar si la presencia histórica del imaginario de la ruralidad puede ser concebida o no como una evidencia de la actuación de larga data de este anclaje socio-existencial. Como ya discutimos un ideal puede o no constituirse en un anclaje socio-existencial. Pero, si ello fuera el caso le daría una cualidad especialmente relevante para entender su carácter histórico desde una perspectiva diacrónica, lo que permitiría analizar sus eventuales transformaciones y aportaría al análisis de procesos de cambio de larga duración. Investigaciones futuras podrían aportar a esta relevante perspectiva. 


\section{Kathya Araujo}

\section{REFERENCIAS BIBLIOGRÁFICAS}

ADORNO, Theodor et al. (1965), La Personalidad Autoritaria. Buenos Aires, Proyección. AMRANI, Younes; BEAUD, Stéphane. (2004), Pays de Malheur!. Paris, La Découverte.

ARAUJO, Kathya. (2009a), Habitar lo Social. Usos y Abusos en la Vida Cotidiana en Chile Actual. Santiago, LOM Ediciones.

. (2009b), “El Ordinario Trabajo Moral del Sujeto”, en K. Araujo (ed)., ¿Se Acata pero no se Cumple? Estudios sobre las Normas en América Latina. Santiago, LOM, pp. 91-117.

. (2013), “La Igualdad en el Lazo Social: Procesos Sociohistóricos y Nuevas Percepciones de la Desigualdad en la Sociedad Chilena". DADOS - Revista de Ciências Sociais, vol. 56, no 1, pp. 109-132.

ARAUJO, Kathya; MARTUCCELLI, Danilo. (2012), Desafíos Comunes. Retrato de la Sociedad Chilena y sus Individuos. Santiago, LOM Ediciones, 2 tomos.

BAJOIT, Guy. (2009), Socio-analyse des Raisons d'Agir. Laval, Presses Universitaires de Laval.

BANCO CENTRAL DE CHILE. (2010), Endeudamiento de los Hogares en Chile: Análisis e Implicancias para la Estabilidad Financiera. Informe de Estabilidad Financiera, Santiago, BCR.

(2013), Encuesta Financiera de Hogares: Metodología y Principales Resultados, EFH 2011-12, revisado el 02 de febrero, 2015 en http://www.bcentral.cl/estadisticas-economicas / financiera-hogares/pdf/Resultados_EFH_2011-12.pdf.

BAROZET, Emanuelle. (2006), “El Valor Histórico del Pituto: Clase Media, Integración y Diferenciación Social en Chile". Revista de Sociología, no 20, pp. 69-96.

BARROS, Paula. (2009), “ ¿Tres Cuotas, Precio Contado? Observaciones sobre el Endeudamiento de los Chilenos", en C. Fuentes (ed.), Chile 2008: Percepciones y Actitudes Sociales. 4o Informe de Encuesta Nacional UDP. Santiago, Universidad Diego Portales, pp. 81-90.

BAUMAN, Zygmunt. (2001), The Individualized Society. Oxford, Polity Press.

BECK, Ulrick. (1998) [1986], La Sociedad del Riesgo. Barcelona, Paidós.

BECK, Ulrich; BECK-GERNSHEIM, Elisabeth. (2003), La Individualización. Barcelona, Paidós.

BENGOA, José. (2009), La Comunidad Perdida. Identidad y Cultura: Los Desafíos de la Modernización Chilena. Santiago, Catalonia.

BOURDIEU, Pierre. (1989), La Distinción. Madrid, Taurus.

BOURDIEU, Pierre; WACQUANT, Loïc. (1995), Respuestas por una Antropología Reflexiva. México, Editorial Grijalbo.

DUMONT, Louis. (1987), Ensayos sobre el Individualismo. Madrid, Alianza.

ECHEVERRÍA, Francisca. (2015), Endeudamiento y Pobreza en Chile. Informe Social № 1. Santiago, Idea Pais.

EHRENBERG, Alain. (2000), La Fatiga de Ser uno Mismo. Buenos Aires, Nueva visión. 
Los Anclajes Socio-existenciales: El Caso de las Expectativas de Futuro

(2010), La Société du Malaise. Paris, Odile Jacob.

ELLIOTT, Anthony. (2003), Critical Visions. Maryland, Rowman \& Littlefield Publishers.

ELLIOTT, Anthony; LEMERT, Charles. (2006), The New Individualism. Oxon, Routledge.

FOUCAULT, Michel. (1983), Vigilar y Castigar. París/México, Siglo XXI.

. (1999a), "El Retorno de la Moral”, en M. Foucault, Obras Esenciales. Volumen III. Estética, Ética y Hermenéutica. Barcelona, Paidós.

. (1999b) [1984], "La Ética del Cuidado de Si como Práctica de la Libertad" en M. Foucault, Obras Esenciales. Volumen III. Estética, Ética y Hermenéutica. Barcelona, Paidós.

. (2005), La Hermenéutica del Sujeto. Madrid, Akal.

(2006), Seguridad, Territorio y Población. Buenos Aires, FCE.

FREUD, Sigmund. (1974) [1921], “Psicología de las Masas y Análisis del Yo" en Obras Completas, Madrid, Biblioteca Nueva.

. (1999) [1856-1939], El Malestar en la Cultura. Madrid, Biblioteca Nueva.

FUNDACIÓN SOL. (2014), Minuta de Empleo no 40 Enero-Marzo. Santiago, Fundación Sol.

GAUlEJAC, Vincent de. (1987), Névrose de Classe. Paris, Hommes \& Groupe Éditeurs.

(2009), Qui est «Je»?. Paris, Seuil.

GAULEJAC, Vincent de; HANIQUE, Fabienne; RICHE, Pierre (eds.). (2007), La Sociologie Clinique. Toulouse, Erès.

GIDDENS, Anthony. (1998) [1992], La Transformación de la Intimidad. Madrid, Editorial Cátedra.

(1997), Modernidad e Identidad del Yo. Barcelona, Península.

GOFFMAN, Erving. (1983), "The Interaction Order". American Sociological Review, vol. 48 , no 1 , pp. 1-17.

. (2006a) [1959], La Presentación de la Persona en la Vida Cotidiana. Buenos Aires, Amorrortu.

(2006b), Frame Analysis. Los Marcos de la Experiencia. Madrid, CIS

GROSS, Peter. (1994), Die Multioptionsgessellschaft. Frankfurt am Main, Suhrkamp.

HARVEY, David. (2007), A Brief History of Neoliberalism. Oxford, Oxford University Press.

INE. (2009), Encuesta Exploratoria de Uso del Tiempo en el Gran Santiago. Revisado el 20 de junio de 2016 en: http:/ / www.ine.cl/canales/chile_estadistico/estadisticas_sociales_culturales/encuesta_tiempo_libre/pdf/enfoqueãeutãpag.pdf.

KAUFMANN, Jean-Claude. (2001), Ego. Paris, Nathan.

KIPPELE, Flavia. (1998), Was heisst Individualisierung? Die Antworten Soziologischer Klassiker. Opladen/Wiesbaden, Westdeutscher Verlag.

KOSELLECK, Reinhart. (1993), “Espacio de Experiencia y 'Horizonte de Expectativa'. Dos Categorías Históricas", en R. Koselleck, Futuro Pasado. Para una Semántica de los Tiempos Históricos. Barcelona, Paidós, pp. 333-357.

DADOS - Revista de Ciências Sociais, Rio de Janeiro, vol. 61, n² 2, 2018 


\section{Kathya Araujo}

KRON, Thomas (ed). (2000), Individualisierung und soziologische Theorie. Opladen, Leske und Budrich.

LAHIRE, Bernard. (2002), Portraits Sociologiques. Paris, Nathan.

(2004a), El Hombre Plural. Barcelona, Bellaterra.

. (2004b), La Culture des Individus. Paris, La Découverte.

LASCH, Christopher. (1999), La Cultura del Narcisismo. Santiago, Andrés Bello.

LE BART, Christian. (2009), L'Individualisation. Paris, Presses de Sciences Po.

LIPOVETSKY, Gilles. (2003), La Era del Vacío. Barcelona, Anagrama.

MARCUSE, Herbert. (1998), El Hombre Unidimensional. Barcelona, Ariel.

MÁRQUEZ, Francisca. (2003), Identidad y Fronteras Urbanas en Santiago de Chile. Documento de Trabajo, Santiago, SUR.

. (2012), "Santiago de Chile: Ciudad Propia, Ciudad Bárbara”. Bitácora, vol. 20, no1, pp. 21-30.

MARTUCELLI, Danilo. (2005), La Consistance du Social. Rennes, P.U.R.

(2006), Forgé par l'Épreuve. Paris, Armand Colin.

(2007), Gramáticas del Individuo. Madrid, Losada.

(2010a), La Societé Singulariste. Paris, Armand Colin.

(2010b), ¿Existen Individuos en el Sur?. Santiago, LOM.

MAYOL, Alberto; AZÓCAR, Carla; AZÓCAR, Carlos. (2013), El Chile Profundo. Modelos Culturales de la Desigualdad y sus Resistencias. Santiago de Chile, Liberalia Ediciones.

MÉNDEZ, María Luisa. (2008), “Middle Class Identities in a Neoliberal Age: Tensions between Contested Authenticities". The Sociological Review, vol. 56, no2, pp. 220-237.

(2009), "Clases Medias y Éticas de la Autenticidad", en C. Fuentes (ed.), Informe Encuesta Nacional de Opinión Pública UDP 2008. Santiago, Ediciones UDP, pp.91-100.

MERTON, Robert. (2002). Teoría y Estructuras Sociales. México, Fondo de Cultura Económica.

NOLLMAN, Gerd; STRASSER, Hermann (eds.). (2004), Das individualisierte Ich in der modernen. Gessellschaft, Frankfurt am Main, Campus.

NÚÑEZ, Javier; GUTIÉRREZ, Roberto. (2004), “Class Discrimination and Meritocracy in the Labor Market: Evidence from Chile". Estudios de Economía, vol. 31, no 2 pp. $113-132$.

OECD (Organisation for Economic Co-operation and Development). (2015), OECD Data. Indicators: Hours Worked. Disponible en: http:/ / data.oecd.org/emp/hoursworked.htm, visitada el 30 de enero, 2016.

OTERO, Marcelo. (2012), L'Ombre Portée. Montréal, Les Editions du Boréal.

PARSONS, Talcott. (1964), Social Structure and Personality. New York, The Free Press.

PORTOCARRERO, Gonzalo. (2006), “Problematizando la Subjetividad”, en X. Díaz; L. Godoy; A. Stecher; J. P. Toro (eds.), Trabajo, Identidad y Vínculo Social. Santiago, Centro de Estudios de la Mujer, Universidad Diego Portales. 
RAMOS, Claudio. (2009), La Transformación de la Empresa Chilena. Santiago, Universidad Alberto Hurtado.

RIESMAN, David et al. (1981) [1950], La Muchedumbre Solitaria. Barcelona, Paidós.

SCHROER, Markus. (2000), Das Individuum der Gesellschaft. Frankfurt am Main, Suhrkamp.

SENNETT, Richard. (2011), El Declive del Hombre Público. Barcelona, Anagrama.

SIMMEL, Georg. (2001), "Las Grandes Urbes y la Vida del Espíritu”, en G. Simmel, El Individuo y la Libertad. Barcelona, Península, pp. 375-398.

SIMONSON, Julia. (2004), Individualisierung und soziale Integration. Zur Entwiclung der Sozialstruktur und iheres Integrationsleistungen. Wiesbaden, Deutscher Universität-Verlag.

STECHER, Antonio; GODOY, Lorena (eds.). (2014), Transformaciones del Trabajo. Subjetividades e Identidades. Santiago de Chile, RIL.

ZIZEK, Slavoj. (1992), El Sublime Objeto de la Ideología. México, Siglo XXI.

(2001), El Espinoso Sujeto. Barcelona, Paidós.

DADOS - Revista de Ciências Sociais, Rio de Janeiro, vol. 61, n² 2, 2018 


\title{
Kathya Araujo
}

RESUMO

As âncoras sócio-existenciais: o caso das expectativas futuras

O objetivo deste artigo é discutir o trabalho que os indivíduos desenvolvem para se sustentar na vida social, enfocando a questão das "âncoras sócio-existenciais" e, em particular, sobre um deles: as expectativas do futuro. Após uma revisão do debate teórico e com base nos resultados de uma pesquisa empírica qualitativa para o caso do Chile, o texto analisa a forma como na sociedade chilena a figura da ida ao Campo-Sul constitui-se como fundamento dessas expectativas de futuro e atua como uma âncora para as existências sociais. Esta análise permitirá argumentar que as "âncoras sócio-existenciais" estão ativas em indivíduos específicos, mas são socialmente compartilhadas e podem ser entendidas como uma resposta, com nuances de acordo com o grupo social, ao mesmo tempo singular e geral, às exigências estruturais às quais é exposto em um determinado momento histórico.

Palavras-chave: indivíduos, ancoragem sócio-existenciais, expectativas de futuro, Chile

\author{
ABSTRACT \\ The Socio-existential Anchors: The Case of the Future Expectations
}

The goal of this article is to discuss the work that individuals develop to sustain themselves in social life, focusing on the question of "socio-existential anchors", and in particular on one type of these: the expectations of the future. After a review of the theoretical debate and based on the results of a qualitative empirical research for the case of Chile, the text analyzes the way in which the figure of the going to the South-Field is constituted as the foundation of these expectations of the future and acts as an anchor for social existences. This analysis will allow to argue that the "socio-existential anchors" are active in specific individuals but are socially shared and can be understood as a response, with nuances according to social group, at once singular and general, to the structural requirements to which it is exposed at a certain historical moment.

Keywords: individual, socio-existential anchors, future expectations, Chile 


\section{RESUMEN}

Los Anclaje Socio-existenciales: El Caso de las Expectativas de Futuro

El objetivo de este artículo es discutir el trabajo que desarrollan los individuos para sostenerse en la vida social, centrándose en la cuestión de los "anclaje socio-existenciales", y en particular en un tipo de estos: las expectativas de futuro. Luego de una revisión del debate teórico y basándose sobre los resultados de una investigación empírica cualitativa para el caso de Chile, el texto analiza la manera en que en la sociedad chilena la figura de la ida al Sur-Campo se constituye como fundamento de estas expectativas de futuro y actúa como ancla para las existencias sociales. Este análisis permitirá argumentar que los "anclaje socio-existenciales" son activos en los individuos concretos pero son socialmente compartidos y pueden ser entendidos como una respuesta, con matices según grupo social, a la vez singular y general, a las exigencias estructurales a las que se está expuesto en un momento histórico determinado.

Palavras-chave: individuo, anclaje socio-existenciales, expectativas de futuro, Chile 